\title{
ASPECTOS TARIFÁRIOS DO SERVIÇO DE ABASTECIMENTO DE ÁGUA E A PRESTAÇÃO DE SERVIÇO DE SANEAMENTO POR EMPRESAS PRI- VADAS EM MINAS GERAIS
}

\section{TARIFF ASPECTS OF THE WATER SUPPLY SERVICE AND THE PROVISION OF SANI- TATION SERVICES BY PRIVATE COMPANIES IN MINAS GERAIS}

\author{
Maíra Fares Leite \\ Bacharel em geografia pela UFMG, especialista em Saneamento e Tecnologia Ambiental pelo DESA/UFMG e mestre \\ em "Água e Sociedade" pela Universidade de Montpellier/SupAgro/AgroParisTech. Trabalha na COPASA MG há 8 \\ anos, atualmente na coordenação do Programa Pró-Mananciais. \\ Email: mairafares@gmail.com
}

\section{RESUMO}

A proposta deste artigo é analisar aspectos tarifários praticados pelos diferentes prestadores no estado de Minas Gerais como forma de contribuir para uma avaliação dos impactos da Lei 14.026/2020 que atualiza o marco legal do saneamento e altera leis anteriores, como as Leis 11.445/2007 e 11.107/2005, favorecendo a expansão da participação de empresas privadas no setor do saneamento. Foram realizados levantamentos das tarifas de diversos prestadores do estado com o intuito de realizar comparação entre eles. Foi elaborado questionário, respondido por moradores de municípios com prestação privada de saneamento, buscando trazer aspectos avaliativos dos serviços prestados. Considera-se que o assunto foi discutido pela mídia tradicional por meio de ponto de vista único. Por esta análise busca-se trazer novos elementos para o debate, permitindo que se discutam outras soluções para a melhoria na prestação de serviço.

\begin{abstract}
The purpose of this article is to analyze price aspects practiced by different water providers in the state of Minas Gerais. The idea is to contribute to an analyzes of the impacts of Law 14.026/2020, which updates the sanitation law and amends previous laws, such as $11.445 / 2007$ and $11.107 / 2005$, favoring the expansion of the participation of private companies in the sanitation sector. Surveys of the price rates of several providers in the state were carried out in order to make a comparison between them. A questionnaire was developed, answered by residents of municipalities with private sanitation services, seeking to bring up evaluative aspects of the services provided. It is considered that the subject was discussed by the traditional media through a unique point of view. This analysis seeks to bring new elements to the debate, allowing the discussion of other solutions to improve the service provision.
\end{abstract}

Palavras-chave: Saneamento. Tarifa. Água. Privatização. Minas Gerais.

Key word: Sanitation. Tariff. Water. Privatization. Minas Gerais.

\section{INTRODUÇÃO}

Em 15 de julho de 2020 foi publicada a Lei 14.026/2020 que atualiza o marco legal do saneamento e altera leis anteriores, como as Leis $11.445 / 2007$ e 11.107/2005, favorecendo a expansão da participação de empresas privadas no setor do saneamento. Os argumentos utilizados no processo de formulação e aprovação da lei foram basicamente os índices ruins do saneamento no Brasil e a necessidade de criar condições para a iniciativa privada atuar, trazendo os necessários avanços na universalização do saneamento no país.

Esses argumentos foram difundidos pelas grandes mídias e não houve muita controvérsia trazida para o debate público. Conforme trazido por Heller, “....a evidência empírica nem sempre valida a ideia de que os preços da prestação privada se beneficiam de maior eficiência, e a maximização da receita pode levar a preocupações com a acessibilidade econômica na perspectiva dos detentores do direito". (2020, pág. 8).

Analisaremos aspectos tarifários em relação aos diferentes prestadores no estado de Minas Gerais e aspectos qualitativos a partir da opinião de moradores atendidos por empresas privadas de saneamento, buscando contribuir para a contra-argumentação, fortemente vendida pela grande mídia e 
discursos políticos, da privatização do setor como única possibilidade de melhoria na prestação dos serviços.

\section{METODOLOGIA}

Foram feitas consultas à sites de prestadores de serviços de saneamento em Minas Gerais e das agências reguladoras ARSAE MG e ARISB MG. As categorias tarifárias analisadas foram residencial e tarifa social, nos volumes de 10 e $15 \mathrm{~m}^{3}$. Foram também utilizados dados do Sistema Nacional sobre Saneamento - SNIS 2019. A fim de capturar a percepção de moradores, em relação aos serviços prestados, de municípios operados por empresas privadas em Minas Gerais, foi disponibilizado por 7 dias questionário no google forms, divulgado por whatsapp e grupos de facebook.

\section{RESULTADOS ALCANÇADOS}

\subsection{Análise tarifária de água no estado de Minas Gerais}

Devido à grande variação na tarifação de esgoto, em função do nível de atendimento e tratamento, foi analisada apenas a tarifa de água, de 14 prestadores, praticada no estado de Minas Gerais.

Tabela 1: Prestadores de saneamneto analisados

\begin{tabular}{|l|c|l|}
\hline \multicolumn{1}{|c|}{ Natureza jurídica } & Número & \multicolumn{1}{c|}{ Nome } \\
\hline Empresa economia mista & 1 & COPASA MG \\
\hline Empresa pública & 2 & COPANOR MG e CESAMA \\
\hline Administração pública direta & 7 & $\begin{array}{l}\text { SAAE Passos, SAAE Itaúna, SAAE Pirapora, SAAE Itabira, SAAE } \\
\text { Formiga, SAAE Sacramento e SAAE Guanhães }\end{array}$ \\
\hline Autarquia & 1 & DMAE Uberlândia \\
\hline Empresa privada & 3 & $\begin{array}{l}\text { Saneouro, Águas de Pará de Minas e Águas de Santo Antônio do Am- } \\
\text { paro }\end{array}$ \\
\hline
\end{tabular}

Não foi possível encontrar a estrutura tarifária praticada nos outros três municípios com empresas privadas de saneamento (Paraguaçu, Araújos e Bom Sucesso).

De acordo com informações obtidas em sites dos prestadores e de agências reguladoras (ARSAEMG e ARISB-MG), a tarifa residencial mais elevada encontrada, para o consumo de $10 \mathrm{~m}^{3}$ e $15 \mathrm{~m}^{3}$ foi a da Saneouro, no município de Ouro Preto, seguida pela Copasa, para $10 \mathrm{~m}^{3}$, e Águas de Santo Antônio do Amparo, para $15 \mathrm{~m}^{3}$. A tarifa social mais elevada, de $10 \mathrm{~m}^{3}$ e $15 \mathrm{~m}^{3}$, foi a praticada pela Águas de Pará de Minas, seguida pela Copasa, no consumo de $10 \mathrm{~m}^{3}$, e pela Águas de Santo Antônio do Amparo, para consumo de $15 \mathrm{~m}^{3}$.

A tarifa mais baixa encontrada para a categoria residencial de $10 \mathrm{~m}^{3}$ e $15 \mathrm{~m}^{3}$ foi a do SAAE Formiga, seguida pela do DMAE Uberlândia. Na categoria de tarifa social para $10 \mathrm{~m}^{3}$ e $15 \mathrm{~m}^{3}$, a tarifa mais baixa encontrada foi a do SAAE Passos, seguida pela do SAAE Itaúna.

A diferença entre a tarifa mais baixa e a mais alta encontrada na categoria residencial foi de $285 \%$, para $10 \mathrm{~m}^{3}$ e $306 \%$ para $15 \mathrm{~m}^{3}$. Na categoria social, a diferença foi de $216 \%$, para $10 \mathrm{~m}^{3}$ e $358 \%$ na categoria social $15 \mathrm{~m}^{3}$. 
Tarifa água 2021

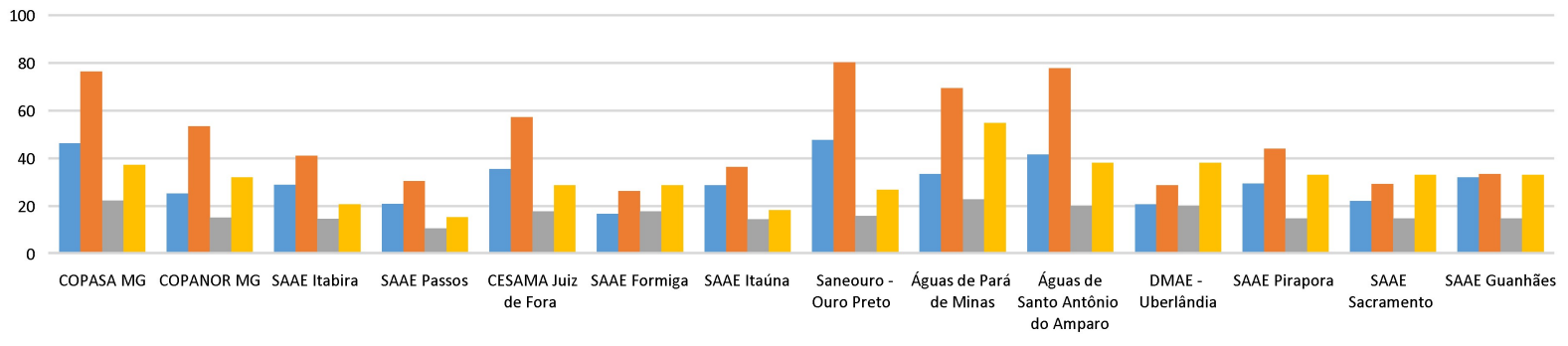

- tarifa residencial - $10 \mathrm{~m}^{3}$ (água) = tarifa residencia - $15 \mathrm{~m}^{3}$ (água) = tarifa social - $10 \mathrm{~m}^{3}$ (água) = tarifa social $15 \mathrm{~m}^{3}$ (água)

Fonte: sites operadores, sites ARSAE MG e site ARISB MG

As tarifas mais altas entre prestadores nas categorias analisadas (residencial e social, para $10 \mathrm{~m}^{3} \mathrm{e}$ $15 \mathrm{~m}^{3}$ ) são aquelas praticadas pelas empresas de capital privado (Saneouro, Águas de Pará de Minas e Águas de Santo Antônio do Amparo) e capital misto (Copasa). As tarifas mais baixas são aquelas praticadas pela administração pública direta ou autarquia (SAAE Formiga, SAAE Passos, SAAE Itaúna e DMAE Uberlândia).

Segundo dados do SNIS, a tarifa média de água mais elevada, em 2019, era a praticada pela COPASA-MG (pessoa jurídica de economia mista), seguida pela Saneouro, Águas de Pará de Minas e Águas de Santo ANtônio do AMparo (empresas privadas) e depois pela Copanor-MG e Cesama (empresas públicas). O indicador é calculado a partir da receita operacional direta de água dividida pelo volume de água faturado. Portanto, são consideradas todas as classes e faixas de consumo, o que pode justificar a diferença nos resultados obtidos, em relação ao gráfico anterior, uma vez que a COPASA-MG tem clientes de alto consumo, se comparado aos pequenos municípios com prestação do serviço privada.

Figura 2: Média dos valores médios da tarufa de água por tipo de prestador em MG, em 2019

\section{Média dos valores médio da tarifa de água por tipo de prestador MG 2019}

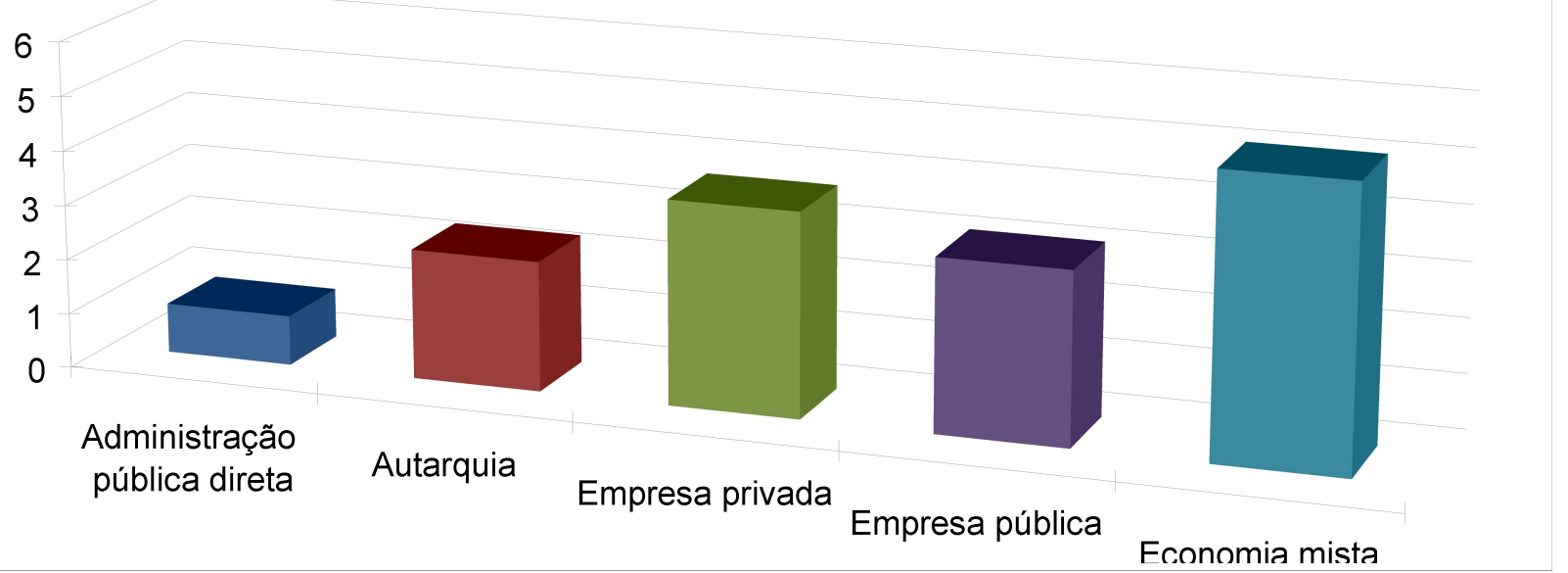

Fonte: SNIS 2019

\subsection{Municípios com serviços de água e esgoto prestado por empresa privada em Minas Gerais}

No estado de Minas Gerais, 6 municípios, até o momento, são operados por empresas privadas, conforme planilha abaixo: 


\begin{tabular}{|c|c|c|}
\hline \multicolumn{3}{|c|}{ 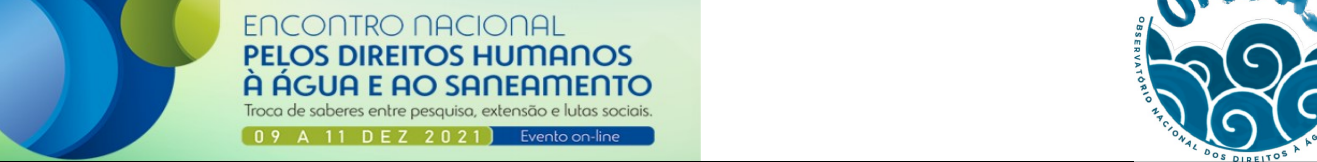 } \\
\hline Prestador & Ano início concessão & Regulação \\
\hline Saneouro - Ouro Preto & 2019 & ARISB-MG \\
\hline Águas de Santo Antônio do Amparo & 2019 & ARISB- MG \\
\hline Águas de Pará de Minas & 2015 & ARSAP \\
\hline Águas de Bom Sucesso & 2002 & - \\
\hline SANARJ - Araujos & 2002 & - \\
\hline COSAGUA - Paraguaçu & 2000 & \\
\hline
\end{tabular}

Fonte: Sites eletrônicos empresas e reguladoras

Visitando os sites das empresas privadas, é possível perceber o baixo número de informações disponíveis, sendo os municípios sem agência reguladora, Bom Sucesso, Araújos e Paraguaçu, com mais baixo acesso à informação.

"O acesso à informação, em si um direito humano, é fundamental para a realização de todos os demais direitos humanos, e construi um pré-requisito para uma participação ativa, livre e significativa.” (ALBUQUERQUE, 2014, pág. 36).

Tabela 3: Informações disponíveis nos sites das empresas privadas prestadoras de serviço de sanemaneto em MG

\begin{tabular}{|l|l|}
\hline \multicolumn{2}{|c|}{ Informações encontradas nos sites das empresas } \\
\hline Saneouro - Ouro Preto & $\begin{array}{l}\text { Agência virtual, informações estrutura operacional, informações de atendimento pre- } \\
\text { sencial, sustentabilidade, estrutura tarifária. }\end{array}$ \\
\hline $\begin{array}{l}\text { Águas de Santo Antônio do } \\
\text { Amparo }\end{array}$ & Emissão de segunda via da conta, estrutura tarifária e contato. \\
\hline Águas de Pará de Minas & $\begin{array}{l}\text { Agência virtual, locais pagamento, estrutura tarifária, qualidade da água, sustentabili- } \\
\text { dade e contato. }\end{array}$ \\
\hline Águas de Bom Sucesso & $\begin{array}{l}\text { Serviços para cliente (emissão de segunda via da conta e histórico de consumo), resul- } \\
\text { tado de análises de qualidade da água, locais para pagamento e contato. }\end{array}$ \\
\hline SANARJ Araújos & $\begin{array}{l}\text { Serviços para cliente (emissão de segunda via da conta e histórico de consumo), resul- } \\
\text { tado de análises de qualidade da água, locais para pagamento e contato. }\end{array}$ \\
\hline COSAGUA - Paraguaçu & $\begin{array}{l}\text { Serviço para cliente (emissão de segunda via da conta), resultado de análises qualida- } \\
\text { de água, locais para pagamento e contato. }\end{array}$ \\
\hline
\end{tabular}

Fonte: sites eletrônicos dos prestadores

Moradores de cinco municípios, dos seis operados por empresas privadas, responderam ao questionário sobre os serviços prestados. O questionário foi respondido por 32 pessoas, sendo $59 \%$ do município de Araújos, 14\% do município de Ouro Preto, 14\% de Santo Antônio do Amparo, 10\% de Bom Sucesso e apenas 3\% de Pará de Minas.

A faixa etária variou de 20 a mais de 60 anos, sendo a maioria entre 41 e 50 anos. Dos entrevistados, $47 \%$ possuem pós-graduação e $30 \%$ têm nível médio de escolaridade. Do total, $37 \%$ disseram que o serviço de água prestado é bom, muito bom ou excelente, enquanto $63 \%$ disseram que o serviço é regular, ruim ou péssimo. $26 \%$ responderam que a qualidade da água distribuída é boa, muito boa ou excelente, enquanto $74 \%$ disseram ser regular, ruim ou péssima.

Do total de respondentes, $23 \%$ disseram que o serviço de esgotamento sanitário prestado é bom, muito bom ou excelente, enquanto $77 \%$ disseram que o serviço é regular, ruim ou péssimo.

Sobre recebimento de água tratada, $74 \%$ responderam que toda a população da cidade recebe água tratada e $23 \%$ responderam que não. Sobre o nível de atendimento com coleta e tratamento de esgoto, $42 \%$ responderam que toda a população é atendida, enquanto $58 \%$ responderam que não.

Sobre a tarifa cobrada, $16 \%$ afirmaram que o valor cobrado é barato ou justo, enquanto $84 \%$ afirmaram ser cara ou abusiva.

Quanto ao acesso às informações pelo operador, 37\% afirmaram ser fácil, enquanto 63\% afirmaram não ser, o que se confirma com as ausências de informações encontradas nos sites dos prestadores. 

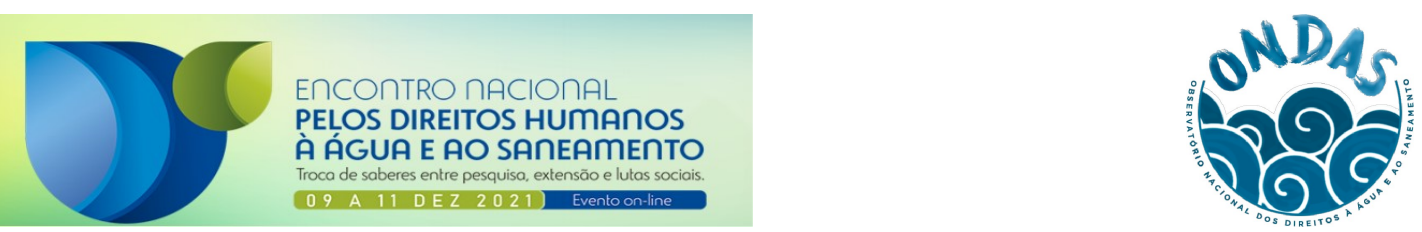

A qualidade do serviço realizado pelo prestador anterior (Copasa ou prefeitura) foi avaliado como bom, muito bom ou excelente por $38 \%$ dos respondentes, enquanto $62 \%$ apontaram como regular, ruim ou péssimo, valores semelhantes às respostas referentes à qualidade do serviço de água do prestador atual.

Em função da baixa amostra de respondentes, os resultados estatísticos, em relação a percepção dos moradores atendidos por municípios com serviços privados, são preliminares.

Figura 3: Resultados da pesquisa com moradores dos municípios operados por prestadores privados em MG.
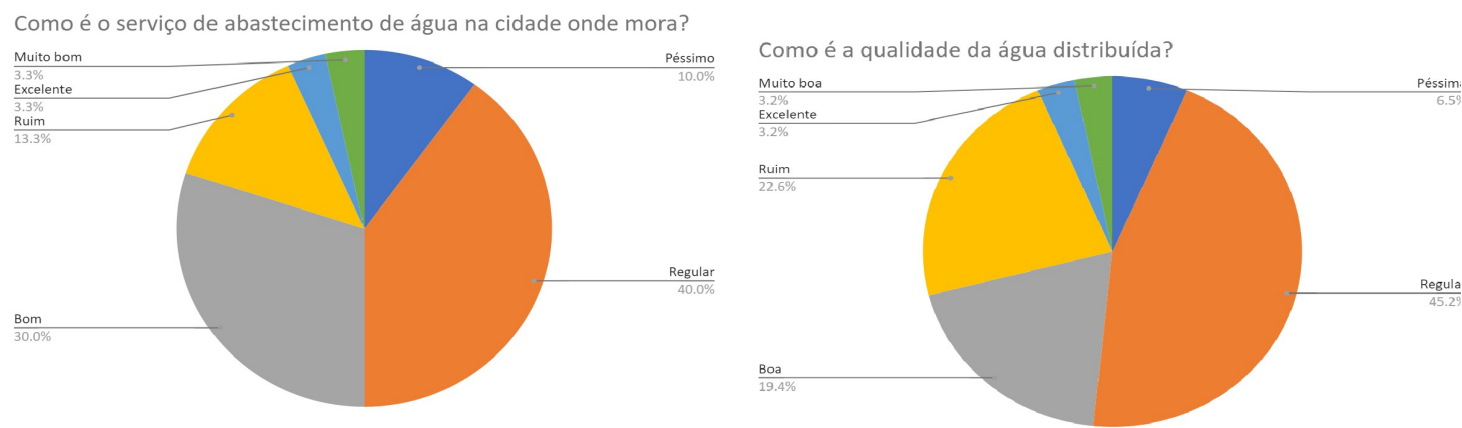

Como é o serviço de esgotamento sanitário na cidade onde mora?

Como é a tarifa de água e esgoto cobrada?
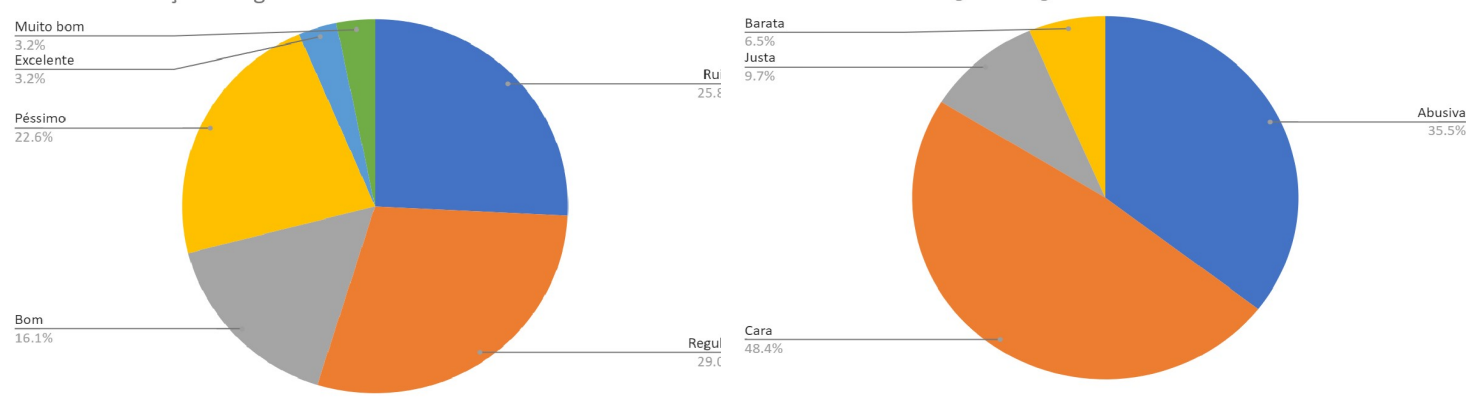

Toda a população tem esgoto coletado e tratado?
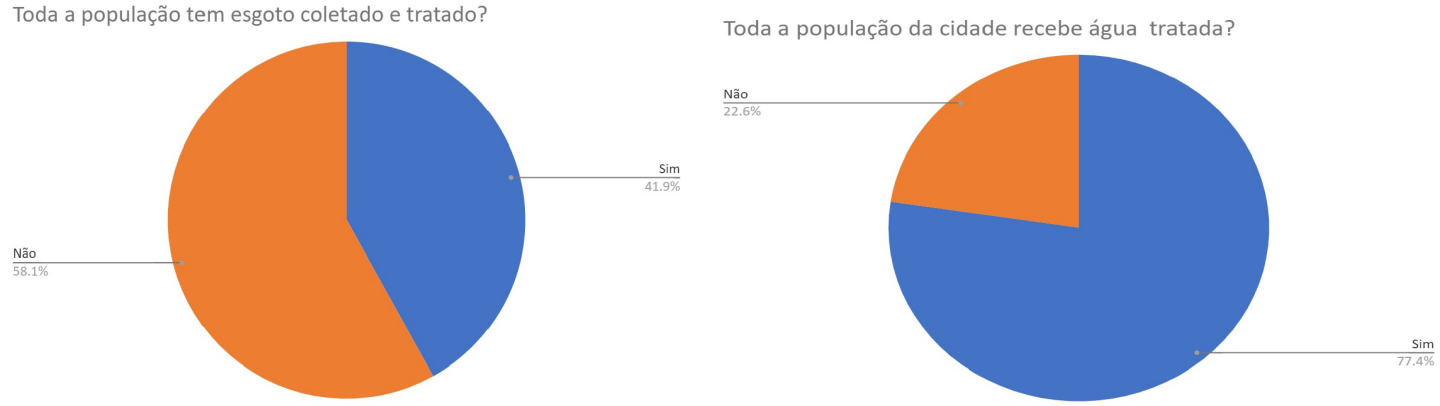

O acesso as informações de saneamento são fáceis (tarifa, paralizações, etc.)?

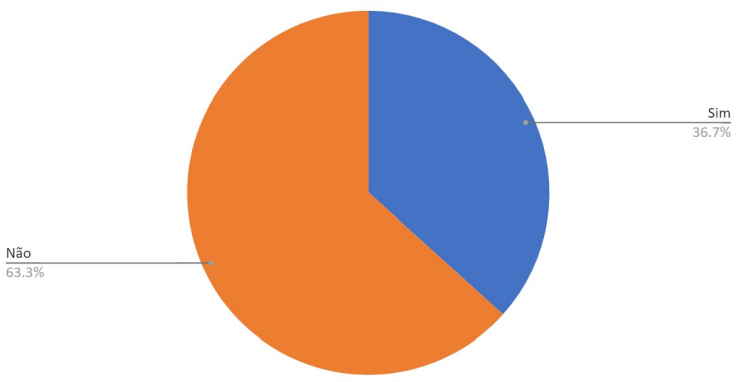

Com era o serviço prestado pelo prestador anterior (prefeitura ou Copasa)?

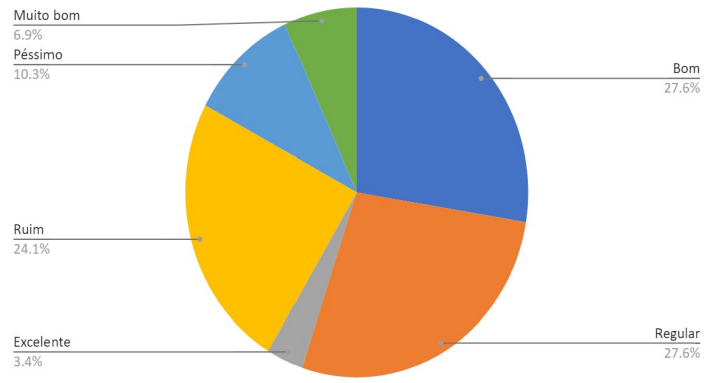

Fonte: Formulário google docs 


\section{CONCLUSÕES}

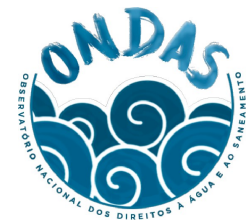

As tarifas praticadas pelas empresas privadas foram as mais altas dentre os prestadores, e as faixas de consumo ( 10 e $15 \mathrm{~m}^{3}$ residencial e social), pesquisados. A média da tarifa média de água em 2019 mais elevada, segundo dados do SNIS, foi da COPASA MG, seguida pelas empresas privadas. Os resultados do questionário apontaram uma percepção de tarifa alta pela população atendida por empresas privadas em Minas Gerais.

A satisfação dos clientes de empresas privadas de saneamento em Minas Gerais, que responderam ao questionário, não se mostrou superior se comparado à satisfação em relação ao serviço prestado anteriormente à chegada das empresas privadas. Aspectos como qualidade do serviço prestado, da água distribuída e do acesso à informação, foram predominantemente apontados como insatisfatórios pelos respondentes. $\mathrm{O}$ esgotamento sanitário se mostrou ser um problema maior se comparado ao abastecimento de água, repetindo tendências do estado e do país.

De maneira geral, o nível de informação encontrado nos sites dos prestadores privados é bastante insuficiente, principalmente das empresas sem agência reguladora atribuída, ferindo princípios de transparência, participação e controle social.

A qualidade do serviço prestado por empresas privadas não se mostrou ser tão efíciente como o apresentado pela grande mídia. O possível aumento de tarifa, que a privatização do setor do saneamento provavelmente trará à população, não foi devidamente debatido publicamente. Portanto, o caminho apresentado como imprescindível para a universalização do saneamento no país, de expansão do setor privado, trará resultados efetivos, operacionais ou trará apenas aumento de tarifa e insatisfação social?

\section{AGRADECIMENTOS}

Agradeço ao ONDAS pelo curso DHAS, que me possibilitou ampliar meus conhecimentos e reflexões sobre o saneamento e a produzir este trabalho. Agradeço às pessoas que responderam ao questionário proposto no decorrer do trabalho e aos amigos que ajudaram a divulgá-lo. Agradeço ao colega Luis Ferreira que foi parceiro no início dessa proposta de trabalho.

\section{REFERÊNCIAS BIBLIOGRÁFICAS}

ALBUQUERQUE, C. Manual prático para a realização dos direitos humanos à água e ao saneamento pela Relatora Especial da ONU, Catarina de Albuquerque. Princípios. Portugal, 2014.

HELLER, L. Direitos humanos e a privatização dos serviços de água e esgotamento sanitário. Relatório do relator especial sobre os direitos humanos à água e ao esgotamento sanitário. 21 de julho 2020.

\section{Inicial - ARSAE MG}

ARISB-MG $\mid$ Home - ARISB-MG Regulação e fiscalização do Saneamento Básico

Cesama - água é vida | Companhia de Saneamento Municipal - Juiz de Fora MG

(DMAE - Portal da Prefeitura de Uberlândia (uberlandia.mg.gov.br

(Águas do Santo Antônio do Amaparo (aguasdoamparo.com.br

SANEOURO

(Início $\mid$ Águas de Pará de Minas (grupoaguasdobrasil.com.br

SANARJ - Concessionária de Saneamento Básico de Araújos

(ÁGUAS DE BOM SUCESSO (aguasdebomsucesso.com.br

COSAGUA - Concessionária de Saneamento Básico Ltda

SNIS - Página inicial 